\title{
Criando Valor Público em Serviços Digitais: uma proposta de conceito
}

\section{Creating Public Value in Digital Services: proposal of a concept}

\author{
Karen Maria Gross Lopes ${ }^{1}$, Edimara Mezzomo Luciano ${ }^{1}$, Marie Anne Macadar ${ }^{2}$
}

\author{
${ }^{1}$ Doutoranda do Programa de Pós-Graduação em Administração, Pontifícia Universidade Católica do Rio Grande \\ do Sul, Porto Alegre, Brasil \\ ${ }^{2}$ Professora do COPPEAD, Universidade Federal do Rio de Janeiro, Rio de Janeiro, Brasil \\ Correspondência: Karen Maria Gross Lopes, Pontifícia Universidade Católica do Rio Grande do Sul, Endereço: \\ Av. Ipiranga, 6681, Bairro Parternon, CEP 90619-900 Porto Alegre, Brasil. Tel: 5551 3320-3524. E-mail: \\ karen.lopes@edu.pucrs.br
}

Recebido: 5 de outubro de 2018 Aceito: 30 de novembro de 2018 Publicado: 31 de dezembro de 2018

DOI: http://dx.doi.org/10.21714/1679-18272018v16Ed.p207-221

\begin{abstract}
Resumo
A criação de valor público por meio de governo digital não é mais uma opção. É necessário que os serviços digitais sejam implementados segundo a perspectiva dos cidadãos e levando em conta os fatores contextuais e sociais. Contudo, o valor público ainda é pouco explorado em investigações científicas brasileiras e em serviços governamentais. $\mathrm{O}$ objetivo deste estudo é explorar o valor público no contexto dos serviços digitais por meio de uma análise sistemática de literatura. $\mathrm{O}$ trabalho contribui com um repertório de significados e fundamentos e com uma proposta de um conceito de valor público na perspectiva do serviço digital. Um conceito mais adequado para valor público em serviço digital é o valor produzido pelo governo, que é percebido pelos cidadãos e criado na adoção dos serviços digitais. Este estudo pode contribuir para abrir caminhos para uma nova linha de pesquisa brasileira em valor público no contexto do governo digital.
\end{abstract}

Palavras-chave: valor público, serviços digitais, governo digital.

\begin{abstract}
Public value creation through digital government is no longer an option. It is necessary that digital service be implemented according to citizens' perception and contextual and social factors. However, public value concept is intricate and still insufficiently used in both public services delivered by government and researches. The goal of this study is to explore public value in digital services delivery through a systematic review of national and international literature. This work contributes with a public value concept based on a repertory of meanings and fundamentals within the national context. We understand that a public value concept that is more adequate to digital services is the value produced by government and perceived by citizens because of the digital services adoption. This study can contribute to create opportunities to a new research line in public value in digital government.
\end{abstract}

Keywords: public value, digital services, digital government. 


\section{Introdução}

Os governos e a comunidade científica brasileira precisam colocar o tema de valor público nas suas agendas. O surgimento da temática de valor público diz respeito à sua abordagem como uma alternativa (STOKER, 2006) ou reação (VAN VEENSTRA, 2012) ao paradigma da New Public Management (NPM). A NPM tem sido criticada por sua comparação entre o setor público e privado, tratando os cidadãos como clientes (ALFORD; HUGHES, 2008). Quando o governo trata os cidadãos como clientes, corre-se o risco de discriminar os cidadãos e falhar nos valores democráticos de imparcialidade e igualdade. Essas críticas à NPM também servem para o contexto do governo digital. Entendemos que os requisitos e a qualidade dos serviços deve ser discutida a partir da perspectiva centrada no cidadão, portanto, do lado da demanda. Isso significa que o governo digital deve ser implementado à luz do valor público, contemplando, assim, as preferências coletivas e não o foco individual da NPM (O'FLYNN, 2007). Ademais, o sucesso do governo digital deve ser baseado no valor criado por meio dos serviços experienciados pelos cidadãos ao usar os serviços digitais (ALSHIBLY; CHIANG, 2015).

Propomos este estudo por conta da oportunidade de promover a perspectiva do cidadão em governo digital, em contraponto a NPM, aliada ao tema de valor público, tema ainda pouco explorado e pouco utilizado como um direcionador de práticas governamentais. Nesse sentido, o objetivo deste ensaio teórico é explorar e compreender as diferentes abordagens de valor público e propor um conceito de valor público associado a serviços digitais governamentais. Portanto, o presente artigo trata da trajetória do valor público, desde o seu surgimento na disciplina de gestão pública até a conexão, a partir de 2003, com a pauta de governo digital. Também exploramos os diferentes conceitos de valor público e o debate quanto à falta de consenso acerca de seu conceito. Desta forma, apresentamos um repertório e nos posicionarmos quanto ao nosso conceito proposto de valor público no âmbito dos serviços digitais. A pesquisa tem enfoque qualitativo e com caráter exploratório. Mapeamos as produções científicas no tema de valor público por meio do emprego de procedimentos metodológicos e técnicas advindas da bibliometria, realizadas na base Web of Science em todo o período da base e localizamos 133 artigos, escritos por 216 autores, vinculados a 137 instituições de 28 países. Dentre eles, constam 20 artigos que tratam especificamente de governo digital associado ao valor público, que se constituem no nosso foco principal de análise.

O presente trabalho está dividido em cinco partes: esta primeira parte composta pela introdução, onde estão inseridos os objetivos e a justificativa da pesquisa. A segunda, a da fundamentação teórica. A terceira apresenta a metodologia da pesquisa. A quarta parte contempla a análise e discussão dos resultados. E, por fim, na quinta parte, apresentamos as considerações finais do trabalho.

\section{A trajetória do Valor Público}

O conceito de valor é usado frequentemente em economia, marketing, contabilidade, estratégia, finanças, estratégia, gestão e sistemas de informação. Já o conceito de valor público é originado da administração pública (AL-HUJRAN et al., 2015). Apesar do conceito de valor público ter emergido há duas décadas, em administração pública, somente há pouco tempo tem atraído mais atenção nesta área (ALFORD; O'FLYNN, 2009). Esta nova abordagem de valor público encoraja os gestores públicos a escutar e engajar o público, como usuários e cidadãos. Embora alguns cidadãos possam não usar tais serviços, muitos outros são capazes de usufruir dos benefícios diretos destes (BLAUG et al., 2006).

O paradigma de valor público teve suas origens em programas de educação executiva da Escola Kennedy de Governo, da Universidade de Harvard. Este obteve novas interpretações como a de Mark Moore (WILLIAMS; SHEARER, 2011), em 1994, no seu artigo "Valor Público como foco da estratégia" e em seu livro "Criando valor público: Gestão estratégica em governo", em 1995. O argumento principal de Moore é que os gestores públicos devem tomar decisões e buscar formas colaborativas de gerar resultados que produzam valor para o público (ALFORD; HUGHES, 2008; WILLIAMS; SHEARER, 2011; CORDELLA; BONINA, 2012). Já para Smith (2004), Moore criou a ideia de valor público, por meio de uma série de estudos em gestão estratégica, nos Estados Unidos. No entanto, Braug et al. (2006) tratam o Livro de Moore (1995) como o trabalho seminal em valor público. Por outro lado, Alford e O'Flynn (2009) afirmam que a abordagem de valor público desenvolveu-se a partir do que se tornou conhecido como "Kennedy Project", no qual Moore participou. Tal projeto tinha como missão desenvolver uma teoria para uso no ensino de executivos do setor público dentro de um programa executivo. Desde então o interesse pelo tema tem aumentado já que as ideias de valor público são 
consideradas uma corrente alternativa importante com uma perspectiva revigorante para o papel do Estado (CORDELLA; BONINA, 2012).

Para Moore (1995, p. 28), "o objetivo do trabalho gerencial no setor público é criar valor público, da mesma forma que o objetivo do trabalho gerencial no setor privado é criar valor privado". Assim, para o autor, a criação de valor público para os cidadãos e a satisfação de suas necessidades deveria guiar as operações dos órgãos públicos na prestação de serviços. A introdução da noção de valor público sugere uma radical mudança nas práticas gerenciais do setor público. $\mathrm{O}$ valor público traz para o centro das ações governamentais a busca de soluções que garantam a melhor coesão possível com as expectativas dos cidadãos (CORDELLA; BONINA, 2012).

Já em relação ao governo digital, a perspectiva do valor público possibilita um melhor entendimento das consequências da utilização das Tecnologias de Informação e Comunicação (TIC) no setor público e modifica a forma de avaliar seu uso, adicionando a abordagem do impacto nas suas dimensões sociais e políticas, as quais são vitais para adoção de TIC no setor público. Os primeiros estudos cujas abordagens associam valor público no contexto do governo digital são: (1) o "Relatório do Setor Público Mundial 2003" da ONU (ONU, 2003) e (2) "Valor Público e e-Governo" de Kearns (2004). Já a pesquisa realizada em artigos científicos na Web of Science (em artigos com revisão por pares), associando os termos "valor público" e "governo digital" somente encontrou artigos a partir do ano de 2006.

Para a ONU (2003), o melhor governo digital é aquele que é visto como um processo de criação de valor público. A ONU (2003, p. 1) indica que o "Governo digital é justificado se ele melhora a capacidade da administração pública de aumentar o fornecimento de valor público, isto é, entregar as coisas que as pessoas querem". Aponta ainda que o modelo de inter-relacionamento entre pessoas, governo e valor público é simples e direto se aplicado a governo: as pessoas expressam suas preferências, o governo usa TIC para melhorar as capacidades de entregar o que as pessoas querem e, no final, um valor público é criado. Contudo, esse modelo é muito difícil de ser aplicado porque os estudos apontam que não há confiança no governo e nem legitimidade de representação. Kearns (2004) fez um estudo relevante, recomendando o uso do valor público associado ao governo digital. Para Kearns (2004, p. 6), "valor público é visto como um framework analítico que se refere ao valor criado para os cidadãos pelo governo e que deve ser usado para tomada de decisão, avaliação de performance e, no contexto de governo digital, como uma ponte entre a tecnologia e as comunidades políticas". O autor entende que o governo digital é frequentemente visto como um processo mecânico de implantação de serviços online e, por conta disso, os benefícios mais amplos do uso de TIC não são levados em consideração. A prontidão dos cidadãos para usar os serviços digitais aumenta se eles percebem que a entrega de serviços públicos economiza tempo e dinheiro, considerando que economizar tempo é um elemento principal do conceito de valor público (AL-HUJRAN et al., 2015). Assim, o uso de TIC no setor público é uma estratégia-chave para alcançar facetas diferentes do valor público, tanto na definição das políticas e no design dos serviços quanto na produção e prestação final (SAVOLDELLI et al., 2014).

\section{Procedimentos Metodológicos}

Uma revisão integrativa de literatura foi base para a fundamentação teórica deste estudo. Com o emprego de técnicas bibliométricas, mapeamos e analisamos a produção científica internacional sobre valor público. Além disso, analisamos os artigos produzidos no Brasil sobre o tema. A seguir, descrevemos as etapas e os procedimentos metodológicos realizados neste estudo.

\subsection{Etapa 1 - Pesquisa dos artigos internacionais de valor público}

A realização da busca de literatura foi feita na base Web of Science (WoS) e na sua sub-base Social Science Citation Index (WoS-SSCI). A partir do critério de busca da palavra-chave "public value", utilizando como estratégia de busca de tópico (busca no título, resumo e palavras-chave), a busca foi realizada em junho de 2017, em todo período disponível na base. Foram encontradas 305 publicações indexadas. Em seguida foram aplicados os seguintes filtros: tipos de documento ("article" ou "review"), todas as categorias, todas as áreas de pesquisa e títulos da fonte ("Public Administration", "Business Economics" e "Information Science Library Science"), totalizando 133 publicações escritas por 216 autores vinculados a 137 instituições em 28 países. Estes artigos foram publicados em 35 periódicos e utilizaram 6.434 referências bibliográficas. Na sequência, os dados 
bibliográficos desses artigos foram exportados para o software HistCite para gerenciamento e análise bibliomética das publicações, permitindo uma análise completa, sem duplicações dos artigos indexados na WoS-SSCI.

\subsubsection{Distribuição temporal}

Conforme a linha cronológica (Figura 1), a primeira publicação ocorreu em 1995. Esta publicação é o artigo de Moore (1994), que juntamente com seu livro de 1995 constituem as referências seminais (WILLIAMS; SHEARER, 2011) da ideia de valor público na sua aplicação na administração pública.

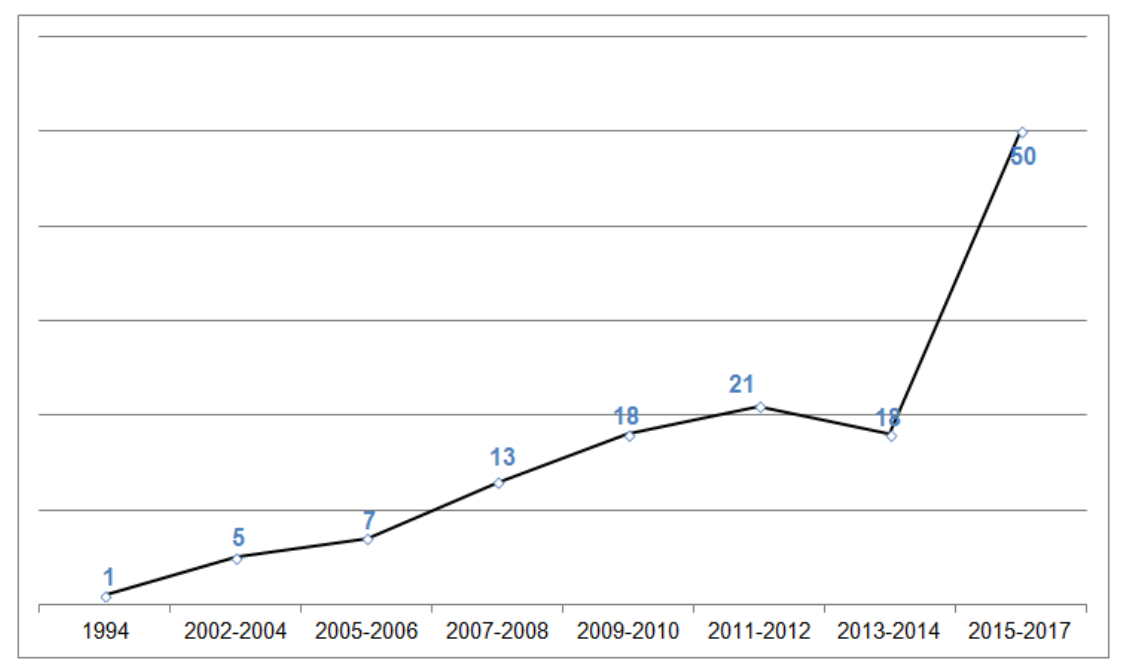

Figura 1 - Distribuição temporal das publicações sobre valor público.

Fonte: Elaborado pelos autores (2017), com base em dados da Web of Science.

Depois disso, até 2002, por oito anos consecutivos, nenhuma publicação foi escrita sobre este tema. E depois, de 2002 até 2008, identificamos um crescimento de mais de 260\%. O crescimento das publicações permanece no período de 2009 e 2012. Porém, o número de publicações aumenta significativamente de 2015 e 2017 , que corresponde ao maior volume de publicações em todo período analisado. Isso evidencia como o tema valor público tem recebido destaque na literatura nestes últimos anos e, portanto, a relevância deste trabalho para área de conhecimento em administração pública.

\subsubsection{Artigos mais citados}

Analisamos os dez artigos mais citados entre os 133 artigos constantes da Tabela 1, para entendimento do surgimento do valor público na disciplina de gestão pública. Posteriormente, analisamos e consideramos conhecimentos advindos de outros artigos citados pelos dez artigos selecionados inicialmente. Mesmo com artigos desde 1994, o artigo de Stoker (2006) tem o maior volume de citações. Já o artigo de Moore (1994), considerado o artigo seminal sobre valor público, está em oitavo lugar em quantidade de citações.

Tabela 1 - Os 10 artigos mais citados sobre valor público (1989 a 2017).

\begin{tabular}{ll|llr}
\hline$N^{\circ}$ & Autores (Ano) & Título & Periódico & $\begin{array}{c}\text { Qtde. } \\
\text { Citações }\end{array}$ \\
\hline & Stoker (2006) & $\begin{array}{l}\text { Public value management - A new } \\
\text { narrative for networked governance? }\end{array}$ & $\begin{array}{l}\text { American Review of } \\
\text { Public Administration }\end{array}$ & 228 \\
\hline
\end{tabular}


Lopes, K. M. G.; Luciano, E. M.; Macadar, M. A. Revista Gestão.Org, v. 16, Edição Especial, 2018. p. 207-221

ISSN 1679-1827

http://www.revista.ufpe.br/gestaoorg

\begin{tabular}{|c|c|c|c|c|}
\hline 2 & $\begin{array}{l}\text { Hefetz e Warner } \\
(2004)\end{array}$ & $\begin{array}{l}\text { Privatization and its reverse: Explaining } \\
\text { the dynamics of the government } \\
\text { contracting process. }\end{array}$ & $\begin{array}{l}\text { Journal of Public } \\
\text { Administration on } \\
\text { Research and Theory }\end{array}$ & 159 \\
\hline 3 & $\begin{array}{l}\text { Jorgensen e } \\
\text { Bozeman (2007) }\end{array}$ & Public values - An inventory. & $\begin{array}{l}\text { Administration } \\
\text { Society }\end{array}$ & 129 \\
\hline 4 & Bozeman (2002) & $\begin{array}{l}\text { Public-value failure: When efficient } \\
\text { markets may not do. }\end{array}$ & $\begin{array}{l}\text { Public Administration } \\
\text { Review }\end{array}$ & 102 \\
\hline 5 & $\begin{array}{l}\text { Alford e Hughes } \\
(2008)\end{array}$ & $\begin{array}{l}\text { Public value pragmatism as the next } \\
\text { phase of public management. }\end{array}$ & $\begin{array}{l}\text { American Review of } \\
\text { Public Administration }\end{array}$ & 71 \\
\hline 6 & $\begin{array}{ll}\text { Williams } & \mathrm{e} \\
\text { Shearer (2011) }\end{array}$ & $\begin{array}{l}\text { Appraising public value: Past, present } \\
\text { and future. }\end{array}$ & Public Administration & 45 \\
\hline 7 & $\begin{array}{l}\text { Cordella e Bonina } \\
(2012)\end{array}$ & $\begin{array}{l}\text { A public value perspective for ICT } \\
\text { enabled public sector reforms: A } \\
\text { theoretical reflection. }\end{array}$ & $\begin{array}{l}\text { Government } \\
\text { Information Quarterly }\end{array}$ & 42 \\
\hline 8 & Moore (1994) & Public value as the focus of strategy. & $\begin{array}{l}\text { Australian Journal of } \\
\text { Public Administration }\end{array}$ & 35 \\
\hline 9 & Smith (2004) & $\begin{array}{l}\text { Focusing on public value: Something } \\
\text { new and something old. }\end{array}$ & $\begin{array}{l}\text { Australian Journal of } \\
\text { Public Administration }\end{array}$ & 35 \\
\hline 10 & $\begin{array}{l}\text { Rhodes e Wanna } \\
\text { (2007) }\end{array}$ & $\begin{array}{l}\text { The limits to public value, or rescuing } \\
\text { responsible government from the } \\
\text { platonic guardians. }\end{array}$ & $\begin{array}{l}\text { Australian Journal of } \\
\text { Public Administration }\end{array}$ & 33 \\
\hline
\end{tabular}

Fonte: Elaborada pelos autores - baseada em dados da Web of Science, junho de 2017

\subsubsection{Periódicos com maior volume de publicações}

A Tabela 2 apresenta as fontes de publicação com mais de cinco artigos publicados em valor público, bem como, a quantidade de citações globais. A soma total de artigos desses periódicos é igual a 64 , o que corresponde a $48 \%$ da quantidade total de 133 artigos encontrados na busca. Dentre as 35 publicações que compõem o corpus da pesquisa, a Australian Journal of Public Administration é que tem maior volume de artigos publicados sobre valor público (16). Em seguida, a Public Administration Review tem 15 artigos publicados e, também, o maior volume de citações.

Tabela 2 - Periódicos com mais de cinco artigos publicados (1989-2017)

\begin{tabular}{l|c|c}
\hline Periódico & Quantidade de Artigos & $\begin{array}{l}\text { Qtde. de Citações } \\
\text { Globais }\end{array}$ \\
\hline Australian Journal of Public Administration & 16 & 329 \\
\hline Public Administration Review & 15 & 357 \\
\hline Public Management Review & 13 & 107 \\
\hline Public Administration & 11 & 271 \\
\hline Government Information Quartely & 9 & 135 \\
\hline TOTAL de ARTIGOS & \multicolumn{2}{|c}{64} \\
\hline
\end{tabular}

Fonte: Elaborada pelos autores - elaborada a partir da Web of Science, junho de 2017 


\subsection{Etapa 2 - Busca dos artigos internacionais de valor público associados a governo digital}

Com o critério de busca da palavra-chave "public value" AND "e-government", utilizando como estratégia de busca de tópico na Web of Science, com os mesmos filtros da pesquisa bibliométrica anterior, localizamos 20 artigos (vide Apêndice A). A análise desses artigos nos permitiu refletir e nos posicionar sobre o conceito de valor público no contexto do governo digital.

\subsection{Etapa 3 - Busca dos artigos nacionais de valor público}

A realização da busca na produção nacional ocorreu em junho de 2017 pela palavra-chave "valor público" na base SPELL, que não retornou nenhum documento. A mesma busca foi realizada, no mesmo período, na base SciELO, com a mesma palavra-chave "valor público" e selecionando "coleções=Brasil'. Essa pesquisa obteve como resultado três artigos brasileiros, conforme a Tabela 3.

Tabela 3 - Os três artigos nacionais sobre valor público

\begin{tabular}{|llll|}
\hline Autores (Ano) & Título & Periódico \\
$\begin{array}{l}\text { Inanime et al. } \\
(2012)\end{array}$ & $\begin{array}{l}\text { Análise do sistema digital de compras do governo federal } \\
\text { brasileiro sob a perspectiva da criação de valor público. }\end{array}$ & $\begin{array}{l}\text { Revista } \\
\text { Administração }\end{array}$ & de \\
\hline Gurgel (2014) & Braverman, o Estado e a "administração consensual”. & Cadernos EBAPE. BR \\
\hline $\begin{array}{l}\text { Porpino e De } \\
\text { Stefani (2014) }\end{array}$ & $\begin{array}{l}\text { O caso do PAC Embrapa: requisitos de uma gestão orientada } \\
\text { para resultados no setor público. }\end{array}$ & $\begin{array}{l}\text { Revista } \\
\text { Administração Pública }\end{array}$ \\
\hline
\end{tabular}

Fonte: Elaborado pelos autores - baseada em dados da SciELO (2017)

O trabalho de Gurgel (2014) e Porpino e De Stefani (2014) tratam valor público no âmbito da administração pública, enquanto o trabalho de Inamine et al. (2012) é o único que utiliza a perspectiva do valor público no contexto do governo digital por meio da análise do sistema digital de compras eletrônicas do Governo Federal Brasileiro.

\subsection{Etapa 4 - Análise crítica}

Após o tratamento dado aos artigos para aplicação das técnicas da pesquisa bibliométrica, iniciamos a leitura integral dos artigos para entendimento das abordagens do valor público na gestão pública, bem como, no contexto do governo digital. Para tanto, procedemos a leitura dos 20 artigos (vide Apêndice A), bem como dos 10 artigos constantes da Tabela 1. Posteriormente, usando a abordagem de snowballing, realizamos a leitura de 74 trabalhos (58 artigos científicos e 16 livros e relatórios), que foram insumo para análise de resultados apresentada a seguir.

\section{Resultados}

Neste tópico analisamos a produção científica internacional sobre valor público, no contexto da gestão pública, em um primeiro momento e, posteriormente, no âmbito do governo digital. No caso das publicações nacionais, a escassez de trabalhos em contraponto a expressiva quantidade produzida internacionalmente, associada à relevância da temática, apontam para a necessidade de ampliação de pesquisa em nível nacional.

\subsection{As diferentes abordagens do valor público na gestão pública}

A análise da literatura revela que há diferenças entre as abordagens de valor público entre os diversos autores. Alguns entendem valor público como sendo um novo paradigma da administração pública, outros como uma teoria normativa e ainda há aqueles que compreendem valor público como um framework de avaliação ou simplesmente como uma perspectiva a ser utilizada nas ações e decisões dos gestores públicos. A seguir destacamos as principais abordagens identificadas nessa investigação. 
O estudo de Kelly et al. (2002) trata da reforma dos serviços públicos na Inglaterra tendo sido referenciado por diversos autores e utilizado como ponto de partida por Stoker (2006), o artigo mais citado em nosso levantamento. Eles abordam o valor público como uma perspectiva ampla de medir o desempenho do governo e orientar as decisões políticas, em uma abordagem holística que incorpora as preferências coletivas. Já o trabalho conduzido por Blaug et al. (2006), denominado "Valor Público, políticas e gestão pública", apresenta valor público como uma abordagem que surgiu da nova teoria de serviços públicos e que deve atender tanto os princípios de eficiência quanto o da democracia. Entendem, ainda, que valor público é uma importante inovação conceitual de prestação de serviço público, como foco em um sistema de governança com o cidadão no centro. Ainda, no mesmo estudo, mencionam valor público como um framework para garantir que as organizações sejam mais responsivas para as necessidades do público.

Moore (1994) é o artigo mais antigo encontrado na pesquisa bibliométrica realizada e aponta o valor público como a tarefa principal do gestor público. Destaca, também, um importante ponto que emerge da exploração da ideia de valor público: a primazia da definição do valor público e que deve ser reservada aos cidadãos e seus representantes. Já, no seu livro, de 1995, Moore trata valor público como um dos três elementos do framework, representado pelo triângulo estratégico. O primeiro elemento do triângulo estratégico é o valor público que representa os objetivos estratégicos; o segundo é o ambiente da administração pública, onde os indivíduos e as organizações operam para alcance do valor público; e o terceiro elemento diz respeito aos recursos e às capacidades operacionais para se atingir os objetivos estratégicos (WILLIAMS; SCHEARER, 2011). Para Rhodes e Wanna (2007) é incorreto tratar valor público como uma teoria já que Moore não deixa claro se de fato é um novo framework teórico, um conceito, um dispositivo heurístico ou ainda uma ferramenta de gestão. Os autores apontam ainda que Moore não buscou tornar o valor público uma teoria empírica ou uma prescrição normativa. Adicionalmente, Rhodes e Wanna (2007) identificam cinco premissas centrais do valor público: (1) funcionários públicos como guardiões do interesse público; (2) primazia da gestão; (3) relevância da experiência do setor privado; (4) o rebaixamento da política e (5) visão benigna das organizações de grande escala.

Já para Alford e Hughes (2008), a nova abordagem da administração pública, denominada "pragmatismo do valor público" vem para resolver o problema das abordagens anteriores que usavam a orientação de "mão única". Para o autor, a melhor abordagem gerencial é a produção de valor que se constitui em um prisma útil por considerar os fins. Alford e O'Flynn (2009), listam quatro abordagens possíveis para o valor público: valor público como um paradigma, como uma retórica, como uma narrativa e, por último, valor público como uma perspectiva sobre o desempenho. Em uma abordagem diferente, Bozeman (2002), foca seu trabalho na ideia de falhas em valor público e, para tanto, cria uma lista de critérios de falha pública. Ainda, Stoker (2006) considera o valor público um novo paradigma da gestão pública como contraponto ao paradigma da NPM. E nessa mesma linha, Cordella e Bonina (2012) traçam um comparativo entre as características dos dois paradigmas da gestão pública conforme apresentado no Tabela 4, a seguir.

Tabela 4 - Paradigmas da gestão pública

\begin{tabular}{|c|c|c|}
\hline & Valor Público & NPM (New Public Management) \\
\hline Base lógica & Administração pública & Gestão privada \\
\hline Foco dominante & $\begin{array}{l}\text { Relacionamentos, promulgação } \\
\text { política }\end{array}$ & Racionalização administrativa, resultados \\
\hline $\begin{array}{ll}\text { Definição } & \text { do } \\
\text { interesse público } & \end{array}$ & Preferências coletivas & Preferências individuais agregadas \\
\hline $\begin{array}{l}\text { Objetivo } \\
\text { Desempenho }\end{array}$ & $\begin{array}{l}\text { Objetivos múltiplos, mudando todo } \\
\text { tempo }\end{array}$ & $\begin{array}{l}\text { Gestão das entradas e saídas para garantir } \\
\text { economia e capacidade de resposta para os } \\
\text { clientes }\end{array}$ \\
\hline $\begin{array}{l}\text { Modelo dominante } \\
\text { de accountability }\end{array}$ & $\begin{array}{l}\text { Sistema de } \\
\text { múltiplo }\end{array}$ & $\begin{array}{l}\text { Accountability crescente via contratos de } \\
\text { desempenho }\end{array}$ \\
\hline $\begin{array}{l}\text { Sistema de entrega } \\
\text { preferencial }\end{array}$ & $\begin{array}{l}\text { Menu de alternativas selecionados } \\
\text { pragmaticamente }\end{array}$ & $\begin{array}{l}\text { Setor privado ou órgãos públicos definidos } \\
\text { rigorosamente }\end{array}$ \\
\hline
\end{tabular}


Criando Valor Público em Serviços Digitais: uma proposta de conceito Revista Gestão.Org, v. 16, Edição Especial, 2018. p. 207-221

ISSN 1679-1827

http://www.revista.ufpe.br/gestaoorg

\begin{tabular}{|lllll|}
\hline \hline Meios & $\begin{array}{l}\text { Cumprimento } \\
\text { objetivos }\end{array}$ & de & múltiplos & Competição \\
\hline Fins & $\begin{array}{l}\text { Cumprimento } \\
\text { sociais }\end{array}$ & de & expectativas & "Governo que trabalha melhor e custa menos" \\
\hline
\end{tabular}

Fonte: Cordella e Bonina, 2012

Diferente de Stoker (2006), Cordella e Bonina (2012) entendem que a NPM pode se constituir em um subconjunto de objetivos do framework de valor público. Para eles, um setor público orientado para a criação de valor público pode priorizar a eficiência e economia, como prega a NPM, mas também se concentrar nas práticas focadas em valor público.

\subsection{A perspectiva de valor público no contexto de governo digital}

No final da década de 90, as iniciativas de governo digital foram impulsionadas pelas experiências do setor privado. O sucesso da adoção de racionalização organizacional e suporte às trocas eletrônicas (e-commerce), foram sem dúvida um estímulo para o engajamento do governo digital nas reformas da NPM. Essa tendência é evidente pela adoção de soluções técnicas e estratégicas em governo digital importadas das experiências do setor privado, focadas na racionalização administrativa e nas práticas gerenciais. Embora as inciativas tenham sido importantes, o foco em eficiência, efetividade e economia nas reformas do setor público são limitadas, subestimando os fatores contextuais e as questões sociais e políticas de sua adoção (CORDELLA; BONINA, 2012). A Tabela 3 apresenta a distribuição temporal dos 20 artigos internacionais que tratam valor público em governo digital.

Tabela 5 - Distribuição temporal das publicações de governo digital com valor público

\begin{tabular}{l|c}
\hline Ano de publicação & Quantidade de artigos \\
\hline 2006 & 1 \\
\hline 2010 & 4 \\
\hline 2012 & 4 \\
\hline 2013 & 1 \\
\hline 2014 & 3 \\
\hline 2015 & 3 \\
\hline 2016 & 2 \\
\hline 2017 & 2 \\
\hline TOTAL & 20 \\
\hline
\end{tabular}

Fonte: Elaborada pelos autores - baseada em dados da Web of Science (2017)

Podemos verificar que a produção científica na temática de valor público no contexto do governo digital é recente, com início a partir de 2006, permanecendo constante nos demais períodos. Contudo, nos parece que, pela sua importância, há uma oportunidade de ampliação do conhecimento e aplicação pelos governos do conceito de valor público, no âmbito do governo digital.

Para Yildiz e Saylam (2013), as questões relativas à demanda e as justificativas de implementação de governo digital estão intimamente relacionadas com o valor público que o governo digital produz. Na mesma linha, Al-Hujran et al. (2015) apontam que a legitimidade do governo digital como um todo depende de quão bem ele cria valor ao produzir resultados, serviços e confiança. Para Karunasena e Deng (2012), o rápido desenvolvimento do governo digital faz com que a adoção do conceito de valor público de uma perspectiva dos cidadãos não é somente apropriado, mas necessário. Alguns autores tratam valor público como forma de avaliação e mensuração do governo digital. Para Karkin e Janssen (2014), a avaliação do governo digital deve incluir uma grande variedade de valores públicos. Por conta do questionamento dos investimentos em iniciativas de governo digital por diversos stakeholders, pesquisas de desenvolvimento de frameworks de avaliação de valor público em governo digital (HEEKS, 2006) têm sido realizadas. Cresswell et al. (2006) analisaram o retorno dos investimentos em TIC pelos governos e propõem um framework de valor público, como um guia para planejar, 
entender e mensurar o valor público.

\section{Discussão dos Resultados}

As abordagens utilizadas para valor público em governo digital nos 20 artigos resultantes da pesquisa na produção científica internacional (Apêndice A) foram analisadas. Dos 14 artigos que declaram sua posição, seis deles entendem que o valor público é um conceito. Três publicações tratam valor público como uma perspectiva. Já duas publicações tratam como teoria e outras duas, como paradigma. Somente um artigo entende que valor público é um framework. Defendemos que a abordagem a ser utilizada para valor público no contexto de governo digital, seja como uma perspectiva. Isso porque incorpora uma significação mais densa que um conceito somente. Além disso, a abordagem como perspectiva permite englobar diferentes nuances, interpretações e aplicações, dada a importante trajetória de valor público trilhada até aqui. Ademais, a abordagem de paradigma parece equivocada, especialmente em uma lógica Kuhniana, onde o paradigma é visto como uma revolução científica que altera a perspectiva histórica da comunidade científica que a experimenta. Já em relação às dificuldades para uma definição consensual para valor público sumarizamos na Tabela 6 o posicionamento de alguns autores.

Tabela 6 - Posicionamentos acerca do conceito de valor público

\begin{tabular}{|l|l|}
\hline Posicionamento quanto ao conceito de valor público & Autor (ano) \\
\hline As ideias de valor público têm tido diferentes entendimentos. & $\begin{array}{l}\text { Cordella e Bonina } \\
(2012)\end{array}$ \\
\hline "O valor público pode ser definido de várias formas”. & $\begin{array}{l}\text { Karunasena e Deng } \\
(2012, p .77)\end{array}$ \\
\hline $\begin{array}{l}\text { Como é uma teoria que ainda está emergindo e se desenvolvendo, ainda não há } \\
\text { consenso sobre o conceito de valor público. }\end{array}$ & PANG et al (2014) \\
\hline $\begin{array}{l}\text { Como conceito e conceituação teórica, valor público é relativamente novo na } \\
\text { administração pública. E ainda, por não ser uma tarefa fácil, parece ser a razão pelo } \\
\text { pouca profundidade e amplitude de conhecimento acumulado sobre valor público. }\end{array}$ & $\begin{array}{l}\text { Karkin e Janssen } \\
(2014)\end{array}$ \\
\hline
\end{tabular}

Fonte: Adaptado de LOPES (2016)

A fim de contribuirmos com uma conceituação para valor público no contexto de serviços digitais, listamos os conceitos das 20 publicações internacionais de valor público associados a governo digital (vide Apêndice A). Observamos que oito desses artigos (40\%) não declaram um conceito de valor público (6) ou apresentam vários conceitos de valor público sem definir um único conceito (2). Verificamos, também, que outros oito artigos (40\%) utilizam conceitos de terceiros: quatro baseados em Mark Moore, autor do artigo seminal de valor público, dois originários de Kelly et al. (2002), um de Al-Hujran (2009) e um do relatório de Accenture (2008). Por fim, somente quatro publicações $(20 \%)$ apresentam seu próprio conceito de valor público. Uma característica presente na maior parte dos conceitos, sejam eles definidos pelo próprio autor, originados de outros autores ou quando vários conceitos são mencionados, é a prestação de serviços como direcionador e gerador de valor público. A alta qualidade dos serviços é considerada como uma fonte de valor público (KEARNS, 2004). Assim, fica claro que este deve ser um elemento fundamental a ser considerado na significação de valor público.

Também chama atenção, dentre os 10 artigos que apontam um conceito, que todos tratam aspectos originados da gestão pública. Esse empréstimo do conceito de valor público de outra disciplina fez sentido por conta da novidade acerca do fenômeno no campo de pesquisa em governo digital. Contudo, passada mais de uma década de estudo e, por conta da relevância como medida de sucesso das iniciativas de governo digital, entendemos que há necessidade de uma conceituação própria para valor público no contexto de governo digital. Nesse sentido, entendemos que o conceito deve, compulsoriamente, tratar de três aspectos, quais sejam: (i) serviços públicos digitais; (ii) perspectiva do cidadão e (iii) percepção e criação de valor público. Em primeiro lugar, os serviços digitais são o principal meio que o governo pode criar valor público no contexto do governo digital. Segundo Yu (2008, p. 160), "o principal objetivo do governo digital é criar valor público ao prestar serviços aos cidadãos, 
http://www.revista.ufpe.br/gestaoorg

empresas e órgãos governamentais". Portanto, os serviços digitais são base fundamental como componentes do conceito de valor público em governo digital. O cidadão é o principal ator que define o valor público e o principal receptor dos serviços digitais (HUI; HAYLLAR, 2010; KARUSENA; DENG, 2012). Desse modo, no que tange ao segundo aspecto, a perspectiva do cidadão, essa é uma característica relevante a ser considerada quando da definição do conceito pela própria natureza do valor público. Por fím, consideramos como premissa fundamental para a significação do conceito, a distinção entre percepção e criação do valor público. A natureza do valor público envolve preferências coletivas (CORDELLA; BONINA, 2012). O cidadão é capaz de perceber benefícios coletivos que não são necessariamente de seu autointeresse (ALFORD; HUDHES, 2008). Assim, o valor público em governo digital pode ser percebido pelos cidadãos como um benefício coletivo, mesmo que não tenha um benefício individual ou mesmo sem a adoção propriamente dita. Dessa forma, o valor público pode ser percebido pelo indivíduo sem necessariamente ser criado diretamente para ele ou utilizado por ele (LOPES, 2016). Além das três premissas anteriores, o trabalho de Al-Hujran et al. (2015) é um insumo importante como base para nossa proposta de conceito, visto que trata o valor percebido pelos cidadãos. Assim, propomos atribuir um conceito para valor público com foco no contexto de governo digital e especialmente em serviços digitais, qual seja: valor público é o valor produzido pelo governo, que é percebido pelos cidadãos e criado na adoção dos serviços digitais.

\section{Conclusões}

Este estudo tem como objetivo explorar e compreender as abordagens de valor público e propor um conceito de valor público associado aos serviços digitais. Trilhamos um percurso entre os fundamentos, abordagens e história da produção de conhecimento de valor público. A partir desse entendimento, dentro das novas interpretações no domínio do governo digital, entendemos que estamos "afiando as ferramentas erradas" ao utilizar as significações e fundamentos da NPM em governo digital. Há de se transformar a visão tecnocentrada, que domina o nosso campo científico e prático das ações governamentais, para a perspectiva do valor público, especialmente na prestação de serviços digitais ao cidadão. A natureza do público é intimamente relacionada aos interesses coletivos, preconizados pela perspectiva do valor público, e não no foco em interesses individuais, como os baseados na NPM. Assim, no que tange ao conceito de valor público, especialmente fundamentado em serviço digital, propomos um conceito específico.

Dentro do exposto acima, urge que o governo e a comunidade científica brasileira discutam uma nova perspectiva de significação de governo digital, dentro de uma agenda de pesquisa voltada ao valor público. Assim, uma análise relevante diz respeito às motivações que levam a academia brasileira a não tratar e priorizar a temática de valor público. Uma primeira razão pode ser pela falta de pesquisa empírica internacional sobre o tema (ALFORD et al., 2016), que pode levar a percepção de baixa aplicabilidade no âmbito do contexto nacional. A segunda razão pode estar relacionada à cultura nacional com foco nas teorias "de fora" e, nesse caso, ao perceber que a produção científica internacional ainda considera o tema complexo, ambíguo e não resolvido (HARTLEY et al., 2016), os pesquisadores brasileiros não priorizem o debate acerca da temática de valor público. Um terceiro motivo para a baixa aplicabilidade do valor público pode residir na dificuldade de estabelecimento de métricas, por meio de valor público, que definam os fins e justifiquem os meios das ações, práticas e políticas públicas e, que pode dificultar a geração de frameworks ou modelos conceituais como instrumentos de medição da criação de valor público.

Também, e não menos importante, se torna a análise da baixa aplicação do valor público no contexto governamental brasileiro. Sabemos que a prática de ouvir a voz ao cidadão tem demonstrado dificuldades de implementação. Ora, tratar valor público significa entender que os árbitros do valor público (MOORE, 2014) se encontram fora do governo. Portanto, devem ser chamados a colaborar, a definir o que é valor público e o que adiciona valor público. Os árbitros são aqui entendidos como agentes de avaliação da criação de valor público, englobando percepções individuais e coletivas. Além disso, o governo deve reconhecer seu papel de garantidor de valor público, especialmente por meio dos serviços públicos digitais. Assim, cada problema social a ser resolvido poderia se constituir em uma oportunidade de criação de valor, mesmo quando considerarmos que os cidadãos frequentemente mudam o grau de importância dos valores públicos. Nessa lógica, os governos terão que criar novos espaços de interação na esfera pública. Assim, gestores públicos devem levantar, junto aos diversos stakeholders, percepções quanto às proposições de valor, em uma lógica preconizada por Alford et al. (2016) como "a busca inquietante de valor". No Brasil, o governo digital tem focado fortemente nas TIC e pouca atenção tem sido dada às aspirações da sociedade, na lógica de colaboração e cocriação cidadã. Tal fato constitui 
um grande paradoxo, onde a busca pela eficiência e pela padronização, facilitadas pelas tecnologias, podem estar gerando um governo digital ineficaz, com baixo impacto ou utilidade ao cidadão.

Finalmente, devemos considerar que as nossas crenças baseadas em um repertório emprestado do mundo privado não são mais suficientes. Não se trata de abandonar totalmente os preceitos da NPM e sim, de forma complementar, incluir os significados do valor público. Assim, usando a metáfora de Kuhn (1962), precisamos incluir mais uma nova peça neste quebra-cabeças chamado governo digital.

Reconhecemos que este estudo apresenta algumas limitações, em especial de cunho metodológico. Quando aplicamos a técnica de snowballing, descrita no tópico 3.4, a fim de estender os artigos com relevância para o escopo desta investigação, não podemos descartar a possibilidade de termos excluídos artigos importantes. Na mesma linha, quando aplicamos critérios de exclusão na pesquisa bibliométrica podemos ter excluído livros, relatórios de governo ou de praticantes, que possam ter contribuição relevante para a questão de pesquisa. Assim, consideramos que futuras pesquisas devam necessariamente incluir tópicos e questões de investigação como uma proposta de agenda de pesquisa focada em valor público, em governo digital e, especialmente, na prestação de serviços digitais sob perspectiva do cidadão.

\section{Referências}

ACCENTURE. (2008). Accenture Global Cities Forum: Exploring People's Perspectives on the Role of Government. Institute of Public Service Value.

ALFORD, J.; HUGHES, O. (2008) Public value pragmatism as the next phase of public management. The American Review of Public Administration.

ALFORD, J.; O'FLYNN, J. (2009) Making sense of public value: Concepts, critiques and emergent meanings. Intl Journal of Public Administration, 32(3-4), 171-191.

ALSHIBLY, H.; CHIONG, R. (2015) Customer empowerment: does it influence electronic government success? a citizen-centric perspective. Electronic Commerce Research and Applications, 14(6), 393-404.

AL-HUJRAN, O. et al. (2015) The imperative of influencing citizen attitude toward e-government adoption and use. Computers in Human Behavior. 53, 189-203.

BLAUG, R.; HORNER, L.; LEKHI, R. (2006). Public value, politics and public management. A Literature Review. London: Work Foundation.

BOZEMAN, B. (2002) Public value failure: When efficient markets may not do. Public administration review, 62(2), 145-161.

CORDELLA, A.; WILLCOCKS, L. (2010) Outsourcing, bureaucracy and public value: Reappraising the notion of the "contract state". Government information quarterly, 27(1), 82-88.

CORDELLA, A.; BONINA, C. M. (2012) A public value perspective for ICT enabled public sector reforms: A theoretical reflection. Government Information Quarterly, 29(4), 512-520.

CORDELLA, A.; WILLCOCKS, L. (2012) Government policy, public value and IT outsourcing: The strategic case of ASPIRE. The journal of strategic information systems, 21(4), 295-307.

CRESSWELL, A. M.; BURKE, G. B.; PARDO, T. (2006) Advancing return on investment, analysis for government IT: a public value framework. Center for Technology in Government, University at Albany, SUNY.

GRIMSLEY, M.; MEEHAN, A. (2007) e-Government information systems: Evaluation-led design for public value and client trust. European Journal of Information Systems, 16(2), 134-148.

GURGEL, C. (2014) Braverman, State, and "consensual administration". Cadernos EBAPE. BR, 12(4), 803-828.

HEEKS, R. (2006) Understanding and measuring e-Government: international benchmarking studies. In: UNDESA workshop, "E-Participation and E-Government: Understanding the Present and Creating the Future", Budapest, Hungary. (5), 27-28.

HEFETZ, A.; WARNER, M. (2004) Privatization and its reverse: Explaining the dynamics of the government contracting process. Journal of Public Administration Research and Theory, 14(2), 171-190. 
HUI, G.; HAYLlaR, M. R. (2010) Creating Public Value in E-Government: A Public-Private-Citizen Collaboration Framework in Web 2.0. Australian Journal of Public Administration, 69(1), 120-131.

HUNG, M. J. (2012) Building Citizen-centred E-government in Taiwan: Problems and Prospects. Australian Journal of Public Administration, 71(2), 246-255.

INAMINE, R; ERDMANN, R. H.; MARCHI, J. J. (2012) Análise do sistema digital de compras do governo federal brasileiro sob a perspectiva da criação de valor público. Revista de Administração, 47(1), 124-139.

JACKSON, P. et al. (2001) Public sector added value: can bureaucracy deliver? Public Administration, 79(1), $5-28$.

JØRGEnsEn, T. B.; BOZEMAN, B. (2007) Public values an inventory. Administration \& Society, 39(3), 354-381.

KARKIN, N.; JANSSEN, M. (2014) Evaluating websites from a public value perspective: A review of Turkish local government websites. International Journal of Information Management, 34(3), 351-363.

KARUNASENA, K.; DENG, H. (2012) Critical factors for evaluating the public value of e-government in Sri Lanka. Government Information Quarterly, 29(1), 76-84.

KEARNS, I. (2004) Public value and e-government. London: Institute for Public Policy Research.

KELlY, G.; MUlGAN, G.; MUERS, S. (2002) Creating Public Value: An analytical framework for public service reform. London: Strategy Unit, Cabinet Office.

KLIEVINK, B.; BHAROSA, N.; TAN, Y. H. (2016) The collaborative realization of public values and business goals: Governance and infrastructure of public-private information platforms. Government Information Quarterly, 33(1), 67-79.

KUHN, T. S. (1962) A estrutura das revoluções científicas. São Paulo: Ed.

LOPES, K. M. G. (2016) Fatores direcionadores para a criação de valor público na adoção de serviços digitais pelo cidadão. Dissertação de Mestrado. Pontifícia Universidade Católica do Rio Grande do Sul.

MEIJER, A. (2015) E-governance innovation: Barriers and strategies. Government Information Quarterly, 32(2), 198-206.

MOORE, M. H. (1994) Public value as the focus of strategy. Australian Journal of Public Administration, 53(3), 296-303.

MOORE, M. H. (1995) Creating public value: Strategic management in government. Harvard university press.

MOORE, G. W.; MOORE, M. H. (2005) Creating public value through state arts agencies.

MOORE, M. H. (2005) Creating public value through private/public partnerships. In: X Congreso Internacional del CLAD, Santiago, Chile.

O'FLYNN, J. (2007) From new public management to public value: Paradigmatic change and managerial implications. Australian journal of public administration, 66(3) p. 353-366.

PANG, M. S.; LEE, G.; DELONE, W. H. (2014) IT resources, organizational capabilities, and value creation in public-sector organizations: a public-value management perspective. Journal of Information Technology, 29(3), 187-205.

PEREIRA, G. V. et al. (2017) Delivering public value through open government data initiatives in a Smart City context. Information Systems Frontiers, 19(2), 213-229.

PORPINO, G.; DE STEFANI, E. (2014) O caso do PAC Embrapa: requisitos de uma gestão orientada para resultados no setor público. Revista de Administração Pública, 48(2), 343-366.

QUINTANILLA, G.; GIL-GARCIA, J. R. (2016) Open Government and Linked Data: Concepts, Experiences and Lessons Based on the Mexican Case. REVISTA DEL CLAD REFORMA Y DEMOCRACIA (65), 69-102.

RAUS, M.; LIU, J.; KIPP, A. (2010) Evaluating IT innovations in a business-to-government context: A framework and its applications. Government Information Quarterly, 27(2), 122-133.

RHODES, R. A.; WANNA, J. (2007) The limits to public value, or rescuing responsible government from the platonic guardians. Australian Journal of Public Administration, 66(4), 406-421. 
SAVOLDELLI, A.; CODAGNONE, C.; MISURACA, G. (2014) Understanding the e-government paradox: Learning from literature and practice on barriers to adoption. Government Information Quarterly, (31), 63-71.

SCOTT, M.; DELONE, W.; GOLDEN, W. (2015) Measuring eGovernment success: a public value approach.

SELTSIKAS, P.; O'KEEFE, R. M. (2010) Expectations and outcomes in electronic identity management: the role of trust and public value. European Journal of Information Systems, 19(1), 93-103.

SMITH, R. F. I. (2004) Focusing on public value: Something new and something old. Australian Journal of Public Administration, 63(4), 68-79.

STOKER, G. (2006). Public value management a new narrative for networked governance? The American review of public administration, 36(1), 41-57.

United Nations Department of Economic and Social Affairs (2003). "World Public Sector Report 2003 E-Government at the Crossroads".

VAN VEENSTRA, A. F. E. (2012). IT-induced public sector transformation. TU Delft, Delft University of Technology.

WILLIAMS, I.; SHEARER, H. (2011) Appraising public value: Past, present and futures. Public Administration, 89(4), 1367-1384.

YILDIZ, M.; SAYLAM, A. (2013) E-government discourses: An inductive analysis. Government Information Quarterly, 30(2), 141-153.

YU, C. C. (2008) Building a value-centric e-government service framework based on a business model perspective. Springer Berlin Heidelberg, 160-171.

\section{Agradecimentos}

O presente trabalho foi realizado com apoio da Coordenação de Aperfeiçoamento de Pessoal de Nível Superior Brasil (CAPES) - Código de Financiamento 001.

\section{APÊNDICE A}

Os 20 artigos de governo digital com uso de valor público dentro da coleção (1989 a 2017)

\begin{tabular}{|c|c|c|c|c|}
\hline $\mathrm{N}^{\mathrm{o}}$ & $\begin{array}{l}\text { Autores } \\
\text { (Ano) }\end{array}$ & $\begin{array}{l}\text { Título e quantidade de Citações } \\
\text { Globais }\end{array}$ & Abordagem & $\begin{array}{l}\text { Conceito de valor público } \\
\text { utilizado }\end{array}$ \\
\hline 1 & $\begin{array}{l}\text { Grimsley e } \\
\text { Meehan } \\
(2007)\end{array}$ & $\begin{array}{l}\text { e-Government information } \\
\text { systems: Evaluation-led design } \\
\text { for public value and client trust } \\
(62)\end{array}$ & Conceito & $\begin{array}{l}\text { Valor Público pode ser interpretado } \\
\text { como valor que os cidadãos e seus } \\
\text { representantes buscam em relação } \\
\text { aos resultados estratégicos e na } \\
\text { experiência dos serviços públicos } \\
\text { (Moore, 1995) }\end{array}$ \\
\hline 2 & $\begin{array}{l}\text { Cordella } \\
\text { Bonina } \\
(2012)\end{array}$ & $\begin{array}{l}\text { A public value perspective for } \\
\text { ICT enabled public sector } \\
\text { reforms: A theoretical reflection. } \\
\text { (42) }\end{array}$ & Paradigma & $\begin{array}{l}\text { Valor Público está relacionado com } \\
\text { as realizações dos objetivos } \\
\text { estabelecidos pelo programas } \\
\text { governamentais e pela entrega de } \\
\text { serviços públicos aos cidadãos. }\end{array}$ \\
\hline 3 & $\begin{array}{l}\text { Karunasena e } \\
\text { Deng (2012) }\end{array}$ & $\begin{array}{l}\text { Critical factors for evaluating the } \\
\text { public value of e-government in } \\
\text { Sri Lanka. (28) }\end{array}$ & Conceito & $\begin{array}{l}\text { Apresenta conceitos de vários } \\
\text { autores, mas não define um } \\
\text { conceito único. }\end{array}$ \\
\hline
\end{tabular}


http://www.revista.ufpe.br/gestaoorg

\begin{tabular}{|c|c|c|c|c|}
\hline 4 & $\begin{array}{l}\text { Cordella e } \\
\text { Willcocks } \\
(2010)\end{array}$ & $\begin{array}{l}\text { Outsourcing, bureaucracy and } \\
\text { public value: Reappraising the } \\
\text { notion of the "contract state". } \\
\text { (25) }\end{array}$ & $\begin{array}{l}\text { Não } \\
\text { declara }\end{array}$ & $\begin{array}{l}\text { Valor Público está relacionado com } \\
\text { as realizações dos objetivos } \\
\text { estabelecidos pelo programas } \\
\text { governamentais e pela entrega de } \\
\text { serviços públicos a cidadania. }\end{array}$ \\
\hline 5 & $\begin{array}{l}\text { Savoldelli et } \\
\text { al. (2014) }\end{array}$ & $\begin{array}{l}\text { Understanding the e-government } \\
\text { paradox: Learning from literature } \\
\text { and practice on barriers to } \\
\text { adoption (13) }\end{array}$ & $\begin{array}{l}\text { Não } \\
\text { declara }\end{array}$ & $\begin{array}{l}\text { Valor público é criado por meio de } \\
\text { serviços, leis e outras ações } \\
\text { (KELLY et al., 2002) }\end{array}$ \\
\hline 6 & $\begin{array}{l}\text { Raus et al. } \\
(2010)\end{array}$ & $\begin{array}{l}\text { Evaluating IT innovations in a } \\
\text { business-to-government context: } \\
\text { A framework and its applications. }\end{array}$ & Conceito & $\begin{array}{l}\text { Apresenta diferentes conceitos, de } \\
\text { acordo com Moore and Moore } \\
\text { (2005), mas não define um conceito } \\
\text { único. }\end{array}$ \\
\hline 7 & $\begin{array}{l}\text { Hui e Hayllar } \\
\text { (2010) }\end{array}$ & $\begin{array}{l}\text { Creating public value in } \\
\text { e-government: } \\
\text { public-private-citizen } \\
\text { collaboration framework in web } \\
\text { 2.0. (12) }\end{array}$ & Conceito & $\begin{array}{l}\text { O valor dos serviços não está } \\
\text { vinculado apenas à qualidade e } \\
\text { eficiência, mas também às } \\
\text { melhorias sociais e econômicos que } \\
\text { eles produzem ao público } \\
\text { (ACCENTURE, 2008). }\end{array}$ \\
\hline 8 & $\begin{array}{l}\text { Karkin e } \\
\text { Janssen } \\
(2014)\end{array}$ & $\begin{array}{l}\text { Evaluating websites from a public } \\
\text { value perspective: A review of } \\
\text { Turkish local government } \\
\text { websites. (11) }\end{array}$ & Perspectiva & $\begin{array}{l}\text { Não declara o conceito de valor } \\
\text { público. }\end{array}$ \\
\hline 9 & $\begin{array}{l}\text { Pang et al. } \\
(2014)\end{array}$ & $\begin{array}{lr}\text { IT resources, } & \text { organizational } \\
\text { capabilities, and value creation In } \\
\text { public sector organisations: a } \\
\text { public-value } \\
\text { perspective. (11) }\end{array}$ & Teoria & $\begin{array}{l}\text { Valor público é criado por meio de } \\
\text { serviços, leis e outras ações } \\
\text { (KELLY et al., 2002) }\end{array}$ \\
\hline 10 & $\begin{array}{l}\text { Seltsikas } \\
\text { O'Keefe } \\
(2010)\end{array}$ & $\begin{array}{l}\text { Expectations and outcomes in } \\
\text { electronic identity management: } \\
\text { the role of trust and public value. } \\
\text { (10) }\end{array}$ & Conceito & $\begin{array}{l}\text { Valor que ultrapassa as rígidas } \\
\text { noções de eficiência e consumo; os } \\
\text { cidadãos estão preocupados e } \\
\text { esperam justiça e equidade nas suas } \\
\text { relações com o governo (Moore, } \\
\text { 1995). }\end{array}$ \\
\hline 11 & $\begin{array}{l}\text { Al-Hujran et } \\
\text { al. (2015) }\end{array}$ & $\begin{array}{l}\text { The imperative of influencing } \\
\text { citizen attitude toward } \\
\text { e-government adoption and use. } \\
\text { (9) }\end{array}$ & Conceito & $\begin{array}{l}\text { O valor público percebido inclui as } \\
\text { percepções dos cidadãos sobre as } \\
\text { melhorias na acessibilidade e } \\
\text { conveniência dos serviços e } \\
\text { informações governamentais } \\
\text { (AL-HUJRAN, 2009). }\end{array}$ \\
\hline 12 & $\begin{array}{l}\text { Cordella e } \\
\text { Willcocks } \\
\text { (2012) }\end{array}$ & $\begin{array}{l}\text { Government policy, public value } \\
\text { and IT outsourcing: The strategic } \\
\text { case of ASPIRE. ( } 7 \text { ) }\end{array}$ & Perspectiva & $\begin{array}{l}\text { Não declara o conceito de valor } \\
\text { público. }\end{array}$ \\
\hline 13 & $\begin{array}{l}\text { Yildiz } \\
\text { Saylam } \\
(2013)\end{array}$ & $\begin{array}{l}\text { E-government discourses: An } \\
\text { inductive analysis. (6) }\end{array}$ & Framework & $\begin{array}{l}\text { Apresenta conceitos de vários } \\
\text { autores, mas não define um } \\
\text { conceito único. }\end{array}$ \\
\hline 14 & Meijer (2015) & $\begin{array}{l}\text { E-governance innovation: } \\
\text { Barriers and strategies. (5) }\end{array}$ & $\begin{array}{l}\text { Não } \\
\text { declara }\end{array}$ & $\begin{array}{l}\text { Não declara o conceito de valor } \\
\text { público. }\end{array}$ \\
\hline
\end{tabular}


Lopes, K. M. G.; Luciano, E. M.; Macadar, M. A. Revista Gestão.Org, v. 16, Edição Especial, 2018. p. 207-221

ISSN 1679-1827

http://www.revista.ufpe.br/gestaoorg

\begin{tabular}{|c|c|c|c|c|}
\hline 15 & $\begin{array}{l}\text { Klievink et } \\
\text { al. (2016) }\end{array}$ & $\begin{array}{l}\text { The collaborative realization of } \\
\text { public values and business goals: } \\
\text { Governance and infrastructure of } \\
\text { public-private information } \\
\text { platforms. (4) }\end{array}$ & $\begin{array}{l}\text { Não } \\
\text { declara }\end{array}$ & $\begin{array}{l}\text { Não declara o conceito de valor } \\
\text { público. }\end{array}$ \\
\hline 16 & $\begin{array}{l}\text { Alshibly e } \\
\text { Chiong }\end{array}$ & $\begin{array}{l}\text { Customer empowerment: Does it } \\
\text { influence electronic government }\end{array}$ & Paradigma & $\begin{array}{l}\text { Não declara o conceito de valor } \\
\text { público. }\end{array}$ \\
\hline 17 & Hung (2012) & $\begin{array}{l}\text { Building } \quad \text { Citizen-centred } \\
\text { E-government in Taiwan: } \\
\text { Problems and Prospects. (1) }\end{array}$ & $\begin{array}{l}\text { Não } \\
\text { declara }\end{array}$ & $\begin{array}{l}\text { Não declara o conceito de valor } \\
\text { público. }\end{array}$ \\
\hline 19 & $\begin{array}{l}\text { Quintanilla e } \\
\text { Gil-Garcia } \\
(2016)\end{array}$ & $\begin{array}{l}\text { Open Government and Linked } \\
\text { Data: Concepts, Experiences and } \\
\text { Lessons Based on the Mexican } \\
\text { Case (0) }\end{array}$ & $\begin{array}{l}\text { Não } \\
\text { declara }\end{array}$ & $\begin{array}{l}\text { Valor público tem três significados } \\
\text { distintos (Moore, 2005). }\end{array}$ \\
\hline 20 & $\begin{array}{l}\text { Pereira et al. } \\
(2017)\end{array}$ & $\begin{array}{l}\text { Delivering public value through } \\
\text { open government data initiatives } \\
\text { in a Smart City contexto }(0)\end{array}$ & Perspectiva & $\begin{array}{l}\text { É a entrega de informações } \\
\text { governamentais e serviços públicos } \\
\text { nas iniciativas de cidades } \\
\text { inteligentes para cidadãos, outros } \\
\text { órgãos e outras entidades. }\end{array}$ \\
\hline
\end{tabular}

Fonte: Os autores - baseada em dados da Web of Science, junho de 2017 